\title{
An Analysis of 10 Gbits/s Optical Transmission System using Fiber Bragg Grating (FBG)
}

\author{
M.A. Othman ${ }^{1}$, M.M. Ismail ${ }^{2}$, H.A. Sulaiman ${ }^{3}$, M.H. Misran ${ }^{4}$, M.A. Meor Said ${ }^{5}$, \\ Y.A. Rahim ${ }^{6}$, A.N. Che Pee ${ }^{7}$, M.R. Motsidi ${ }^{8}$ \\ ${ }^{I}$ Centre for Telecommunication Research and Innovation FakultiKej. ElektronikdanKej.Komputer \\ UniversitiTeknikal Malaysia Melaka Hang Tuah Jaya, 76100 Durian Tunggal Melaka, Malaysia \\ ${ }^{2}$ Fakulti TeknologiMaklumatdanKomunikasi UniversitiTeknikal Malaysia MelakaHang Tuah \\ Jaya, 76100 Durian TunggalMelaka, Malaysia
}

\begin{abstract}
This paper discussed on a simulation of optical transmission system in optical fiber. The optical fiber is always used in telecommunication system because of its characteristics which include small size or dimension, low loss and low interferences from outside environment. There are various types of optical fiber, the Fiber Bragg Grating (FBG) is commonly chosen as important components to compensate the dispersion in optical communication system. FBG is very simple, has low cost filter for wavelength selection and low insertion loss, it has also customized reflection spectrum and wide bandwidth. The simulation of transmission system will be analyzed based on different parameters by using OptiSystem simulator. By simulating a model of communication system and using the most suitable settings of the system which include input power $(\mathrm{dBm})$, fiber cable length $(\mathrm{km})$ and attenuation coefficient $(\mathrm{dB} / \mathrm{km})$ at cable section, there are three different parameters will be investigated which are output power (Watt), noise figure $(d B)$, and gain $(d B)$ at receiver. On the other hand, the frequency at transmitter $(\mathrm{GHz})$ and cut-off frequency (Bit rate $\mathrm{Hz}$ ) at receiver will be fixed earlier as initial setting for the simulation.
\end{abstract}

Keywords: - Optical Transmission System, Fiber Bragg Grating (FBG), Optisystem simulator, parameters

\section{INTRODUCTION}

The basic optical transmission system consists of three basic elements which are fiber media (transmission channel), light sources as the input (convert electric signal into optic signal), and light detector as the output (convert optic signal into electric signal). Fiber Bragg Gratings (FBG) is added for the design of Optical Transmission System. FBG is a key component in optical communication system as, dispersion compensators, filters and flatteners gain. FBG are very attractive components because as well as being passive, linear and compact, retain strong dispersion in both reflection and transmission. In the transmission section, the gratings are placed in the line with the fiber. It will help to achieve the maximum compression ratio [2].

OptiSystem Simulator Software is an advanced, innovative, rapidly developing and powerful software simulator tool for the design, testing and optimization of virtually any type of optical link in the physical layer of a broad spectrum of optical networks from ultra-long-haul system to local area networks (LANs) and metropolitan (MANs) [1]. OptiSystem offers optical transmission system design and planning from component to system level and present the analysis and scenarios visually. It can help the users to plan, test and simulate several applications such as WDM/TDM or CATV network, dispersion map design, transmitter, receiver and amplifier design and others [1]. Optisystem is a product that does not depend on other simulation design. It is based on realistic optical fibermodeling as a communication system. There are hundreds of official components in Optisystem component library.

In this paper, the simulation of the optical transmission system in optical fiber has been discussed by analyzing the effect of the components in data receiver by using different parameters setting. The value of parameters has been investigated such as output power $(\mathrm{dBm})$, noise figure $(\mathrm{dB})$, attenuation coefficient $(\mathrm{dB} / \mathrm{km})$ at cable section and gain $(\mathrm{dB})$ at receiver.

\section{BACKGROUND THEORY}

Fiber optic communication is one way to transmit the information or data from one place to another by sending the pulses of light through an optical fiber. Fiber optic is a natural consequence of the internet growth. Fiber optic act like an optical wire made it as the most suitable for the communication channel. There are three basics of the fiber optic system. Transmitter is to transmit the signal by converting an electrical signal to optical signal. Fiber optic cable is the transmission channel to transmit the data. Receiver is the place to accept the signal from the transmitter. 


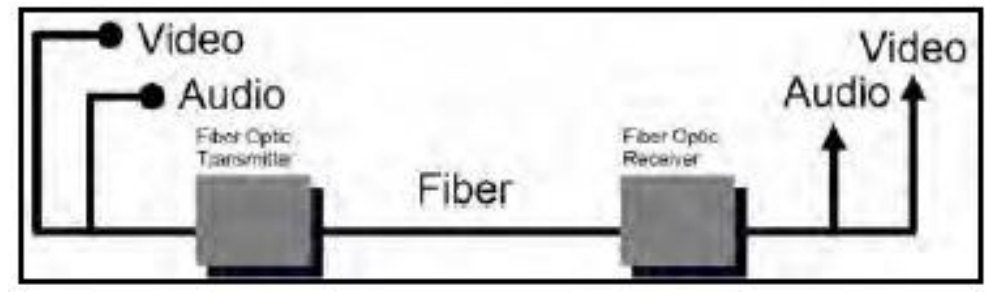

Figure 1: Example of Fiber Optic System. [3]

\section{A. Fiber Bragg Grating (FBG)}

Fiber Bragg Grating (FBG) is very simple and low cost filter for wavelength selection which has various applications to improve the quality and diminish the costs in optical networks [1]. FBG executes some operations like reflection and filtering with high efficiency and low loses [1]. FBG acts as a dispersion compensator in transmission optical system which is used to compensate chromatic dispersion. Thus, the final expected effect is compression in incident pulse and can be appropriate to compensate chromatic dispersion in a communication link[1]. FBG is single mode which will expose the core to the periodic pattern of intense ultraviolet light. The exposure will increase the refractive index and thus the refractive index is permanently increased. Then the exposure pattern will create a fixed index modulation that called grating. When periodic refraction is changed, a small reflected light will be produced. Then, the small reflected light will be combined into a large reflected light at a certain wavelength. The certain wavelength is when the grating period is approximately half the input light's wavelength which is called Bragg's wavelength. The other light (except the Bragg's light) will be transparent. This principle is shown as below in Figure 2 [4].

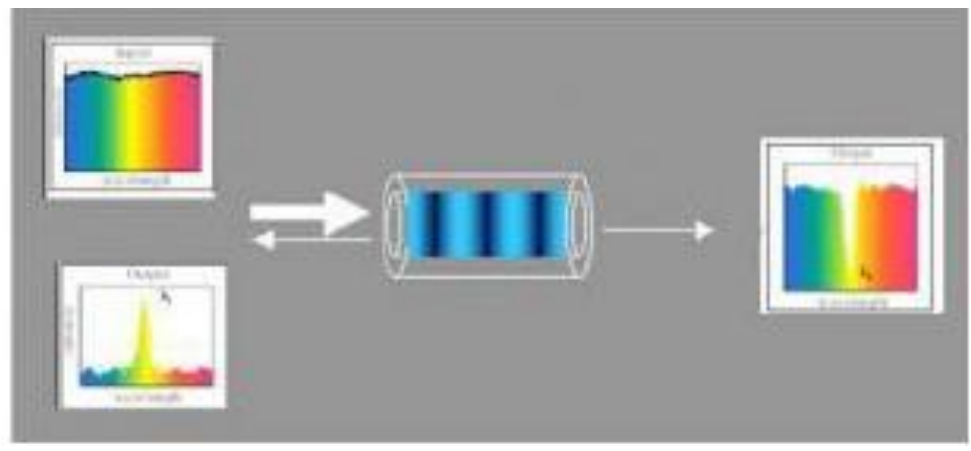

Figure 2: The principle of Bragg's light.

\section{B. Description of Components:}

Non-return-zero (NRZ) pulse generator is used in producing the electrical data signal for the modulation process. It has the ability to fix the bits in the state as the voltage is changing. Therefore, it is easy to indicate where the bits should start and stop. Besides, the NRZ pulse generator has an advantage on controlling bandwidth. This is due to the characteristic of the generator that the returning signals to zero between bits will not wasting the bandwidth of the data signal. Pseudo-random bit sequence generator is used to scramble data signal in terms of bit rates[5]. Operation mode controls the algorithm used to generate the bit sequence, probability: random number generator is used with parameter mark probability of ones in the sequence. Order: a sequence of ones is generated. Zeros: a sequence of zeros is generated. Continuous Wave (CW) laser is applied in the design and externally modulated with a non-return-zero (NRZ) pseudorandom binary sequence in a MachZehnder modulator with the specified extinction ratio. Mach- Zehnder modulator is a modulator based on a principle of interferometry. Constructive and destructive interference at the output ate determined by different paths regarding on the voltage supplied. Thus, the output signal could be modulated regarding to the voltage. Single mode optical fiber is used to allow one mode of light to propagate at a time within a small core radius. It is suitable for a long distance transmission with high speed data. A single data signal could be transmit from 25 to $100 \mathrm{~km}$ in range of fiber length. It is used to transmit the transmission of a single ray or mode of light as a carrier in transmitting an optical signal. Fiber Bragg Grating (FBG) is used to compensate chromatic dispersion of common fibers. FBG is a part of common single mode fiber that is like a grating. Erbium doped fiber amplifier (EDFA) is used to compensate loses in optical transmission system. Photo detector (PIN Photodiode) is used for detection of light (photons) at the receiver by converting light directly into electric current. One photon yields one electron [6]. 


\section{DESIGN CONSIDERATION}

The system is operated with the basic optical communication which consists of a transmitter, transmission link and a receiver. The system transmits information using optical carrier wave from transmitter to receiver via optical fiber. The input signal contains electrical data that is represented by 0's and 1's has been generated by a non-return-zero (NRZ) pseudorandom binary sequence. Then the input signal is modulated with semiconductor laser that is represented by Continuous Wave $(\mathrm{CW})$ laser through Mach- Zehnder modulator. CW laser supplies input signal with $1550 \mathrm{~nm}$ wavelength and input power of $5 \mathrm{dBm}$ which is externally modulated at $10 \mathrm{Gbits} / \mathrm{s}$ with a non-return-zero (NRZ) pseudorandom binary sequence in a Mach-Zehnder modulator with $30 \mathrm{~dB}$ of extinction ratio. The optical fiber used is single mode fiber because single mode fiber can yield higher data rate, less dispersion and also can operate in long haul distance, so it is suitable to be used as transmission link.

For the dispersion compensator, the fiber Bragg grating will be used. The length grating that will be used is $6 \mathrm{~mm}$ since the most proper length for proposed model is equal to $1=6 \mathrm{~mm}$ by try and error method [1]. After dispersion compensation the signal will pass through optical amplifier that represented by Erbium-doped fiber amplifier (EDFA). Optical amplification is required to overcome the fiber loss and also to amplify the signal before receive by Photo detector PIN at the receiver part.

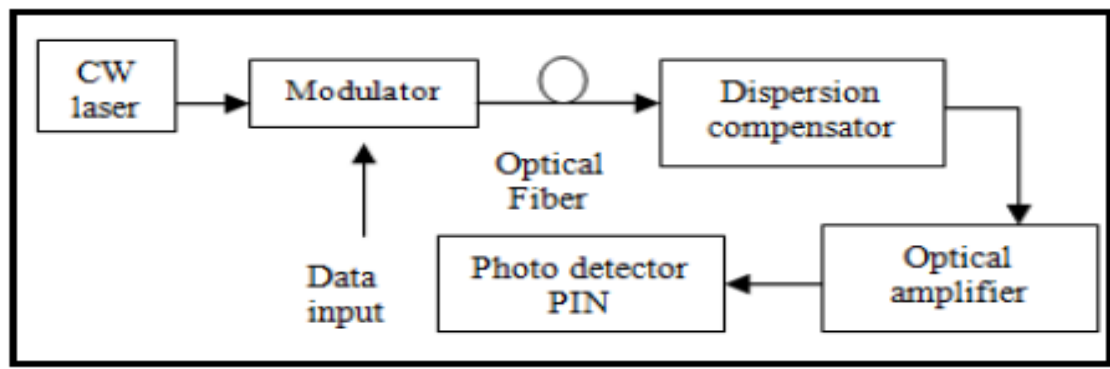

Figure 3: The optical transmission system block diagram.

The initial settings for the design are shown as below in order to operate as the optical transmission system:

Input power: $5 \mathrm{dBm}$

Frequency at transmitter: $1550 \mathrm{~nm}$

Fiber length: $10 \mathrm{~km}$

Attenuation coefficient at cable section: $0.2 \mathrm{~dB} / \mathrm{km}$

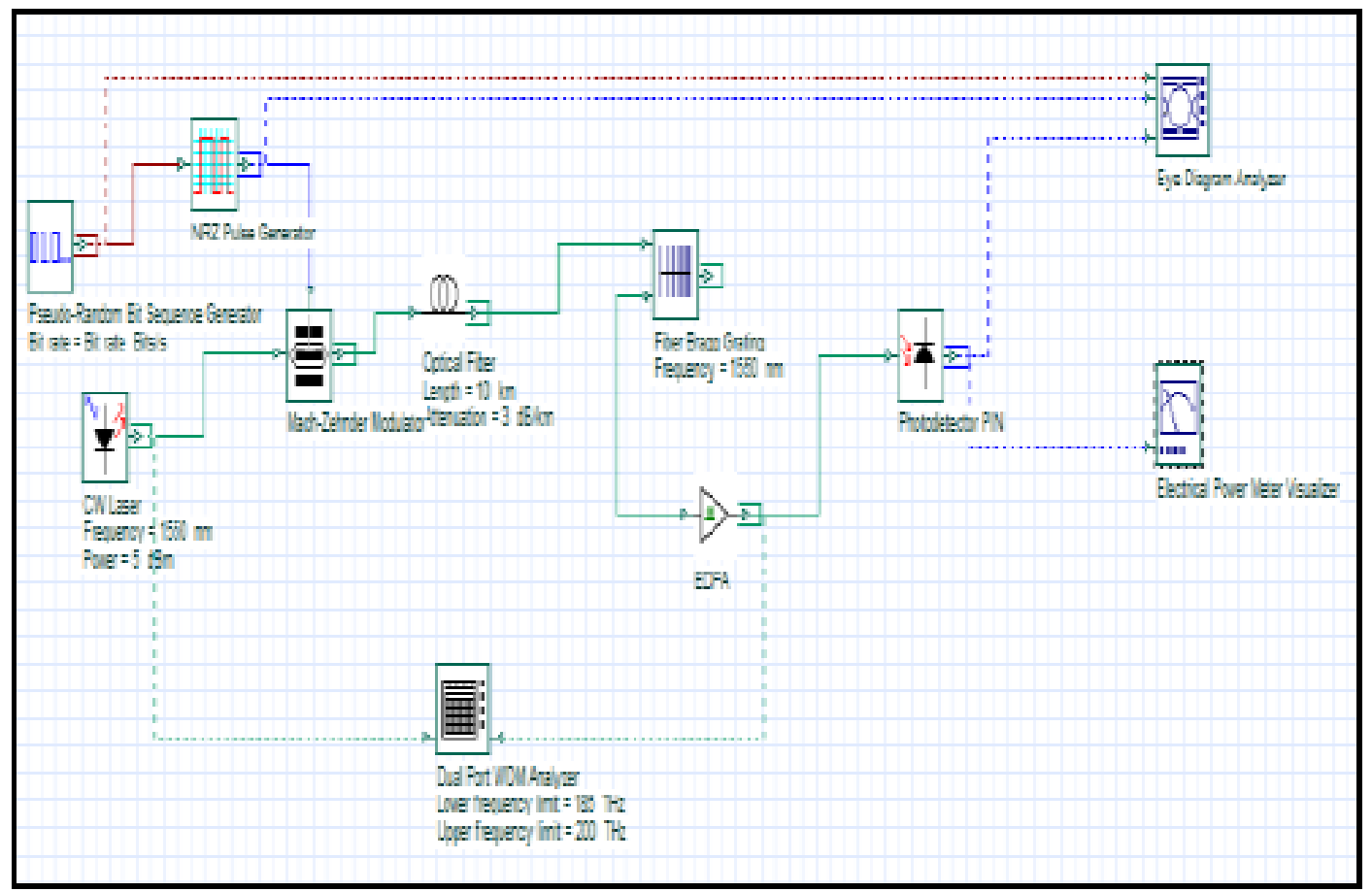

Figure 4: The designed model of simulated system with Optisystem software. 


\section{RESULTS AND DisCUSSIONS}

The simulation and optimization of the design is done by OptiSystem simulation software. The eye diagrams and results of output power, gain $(\mathrm{dB})$ at receiver, noise figure are tabulated into Table 1 until Table 7 by using different values of input power $(\mathrm{dBm})$, attenuation coefficient $(\mathrm{dB} / \mathrm{km})$ at cable section, and fiber cable length $(\mathrm{km})$. The related graphs are also plotted as shown in Figure 5, 6, and 7.

Table 1: The differences of the eye diagram for the design with and without using Fiber Bragg Grating.

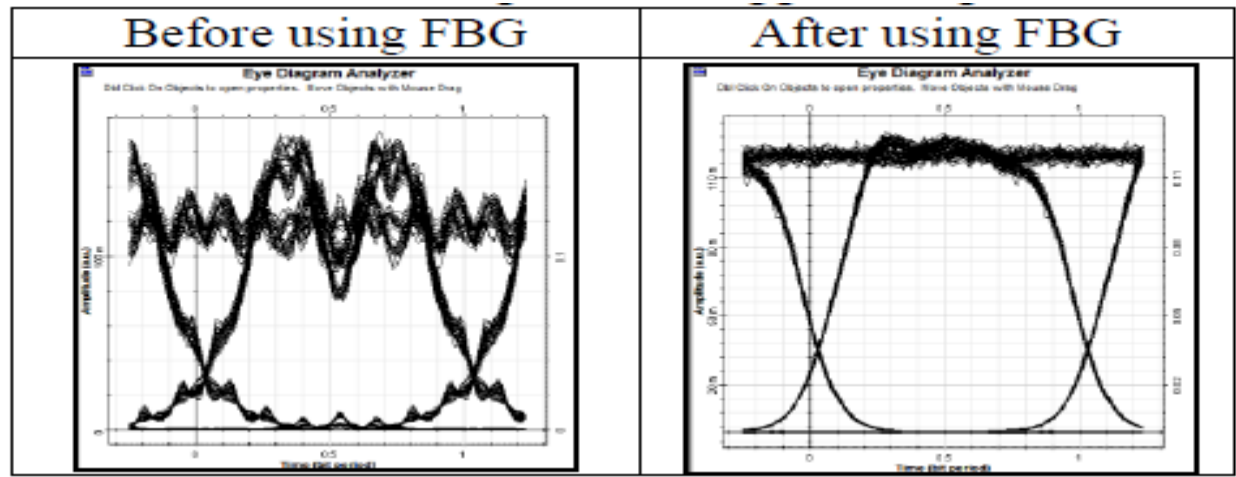

Table 2: The output readings are measured by varying the fiber lengths.

\begin{tabular}{|c|c|c|c|}
\hline $\begin{array}{l}\text { Length } \\
(\mathrm{km})\end{array}$ & $\begin{array}{c}\text { Gain } \\
(\mathrm{dB})\end{array}$ & $\begin{array}{c}\text { Noise Figure } \\
(\mathrm{dB})\end{array}$ & $\begin{array}{c}\text { Output Power } \\
(\mathrm{mW})\end{array}$ \\
\hline 5 & 12.286145 & 11.2715 & 6.320 \\
\hline 10 & 12.239332 & 12.2316 & 6.168 \\
\hline 15 & 12.187612 & 13.2026 & 6.003 \\
\hline 20 & 12.129242 & 14.184 & 5.838 \\
\hline 25 & 12.061326 & 15.1748 & 5.663 \\
\hline 30 & 11.981893 & 16.1742 & 5.480 \\
\hline
\end{tabular}

Table 3: Eye diagrams are analyzed by using different values of fiber length

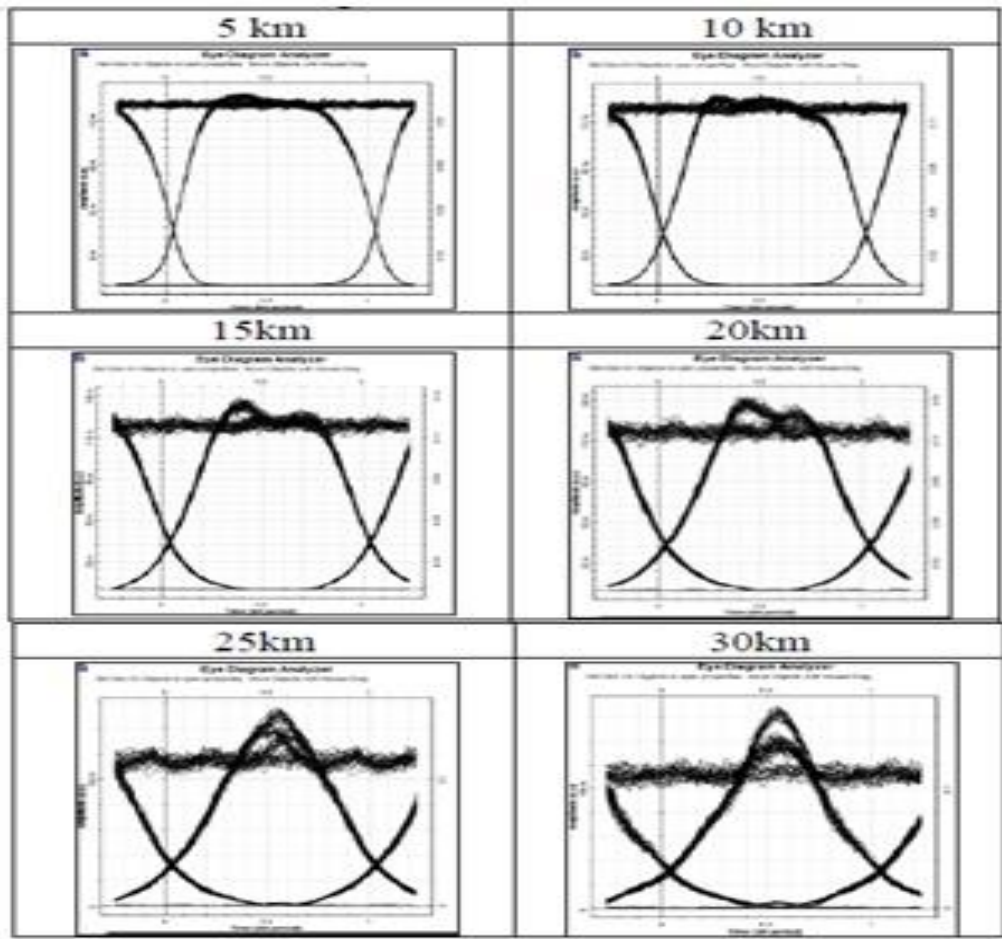

Table 4: The output readings are tabulated by varying the input power. 
Table 4: The output readings are tabulated by varying the input power.

\begin{tabular}{|c|c|c|c|}
\hline $\begin{array}{c}\text { Input } \\
\text { Power } \\
(\mathrm{dBm})\end{array}$ & $\begin{array}{c}\text { Gain } \\
(\mathrm{dB})\end{array}$ & $\begin{array}{c}\text { Noise Figure } \\
(\mathrm{dB})\end{array}$ & $\begin{array}{c}\text { Output Power } \\
(\mathrm{mW})\end{array}$ \\
\hline 1 & 15.980397 & 12.1756 & 5.479 \\
\hline 5 & 12.239332 & 12.2316 & 6.168 \\
\hline 10 & 7.459714 & 12.5654 & 6.815 \\
\hline 15 & 2.7565939 & 13.4194 & 7.789 \\
\hline 20 & -1.6140654 & 15.0246 & 10.46 \\
\hline
\end{tabular}

Table 5: Eye diagrams are analyzed by using different values of input power.
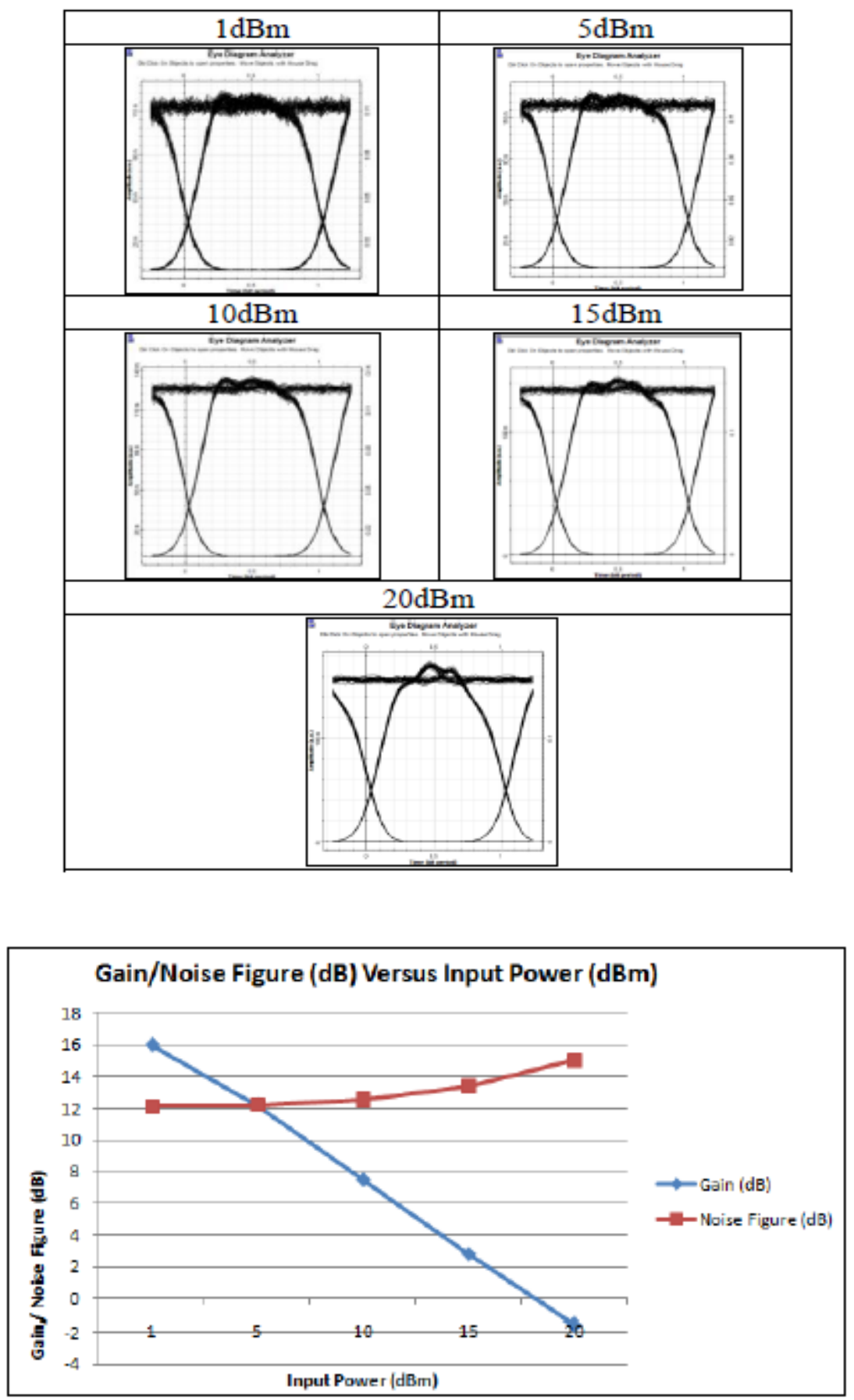

Figure 6: Graph of gain/noise figure versus input power.

www.iosrjen.org 
Table 6: The output readings are obtained by varying the attenuation coefficient at cable section.

\begin{tabular}{|c|c|c|c|}
\hline $\begin{array}{c}\text { Attenuation } \\
\text { coefficient } \\
(\mathrm{dB} / \mathrm{km})\end{array}$ & $\begin{array}{c}\text { Gain } \\
(\mathrm{dB})\end{array}$ & $\begin{array}{c}\text { Noise } \\
\text { Figure } \\
(\mathrm{dB})\end{array}$ & $\begin{array}{c}\text { Output } \\
\text { Power } \\
(\mathrm{W})\end{array}$ \\
\hline 0.2 & 12.239332 & 12.2316 & $6.168 \mathrm{~m}$ \\
\hline 1 & 11.474362 & 20.2576 & $4.343 \mathrm{~m}$ \\
\hline 3 & -1.1871464 & 41.0927 & $15.769 \mu$ \\
\hline 5 & -20.999918 & 61.128 & $1.142 \mu$ \\
\hline
\end{tabular}

Table 7: Eye diagrams are analyzed by using different values of attenuation coefficient at cable section.
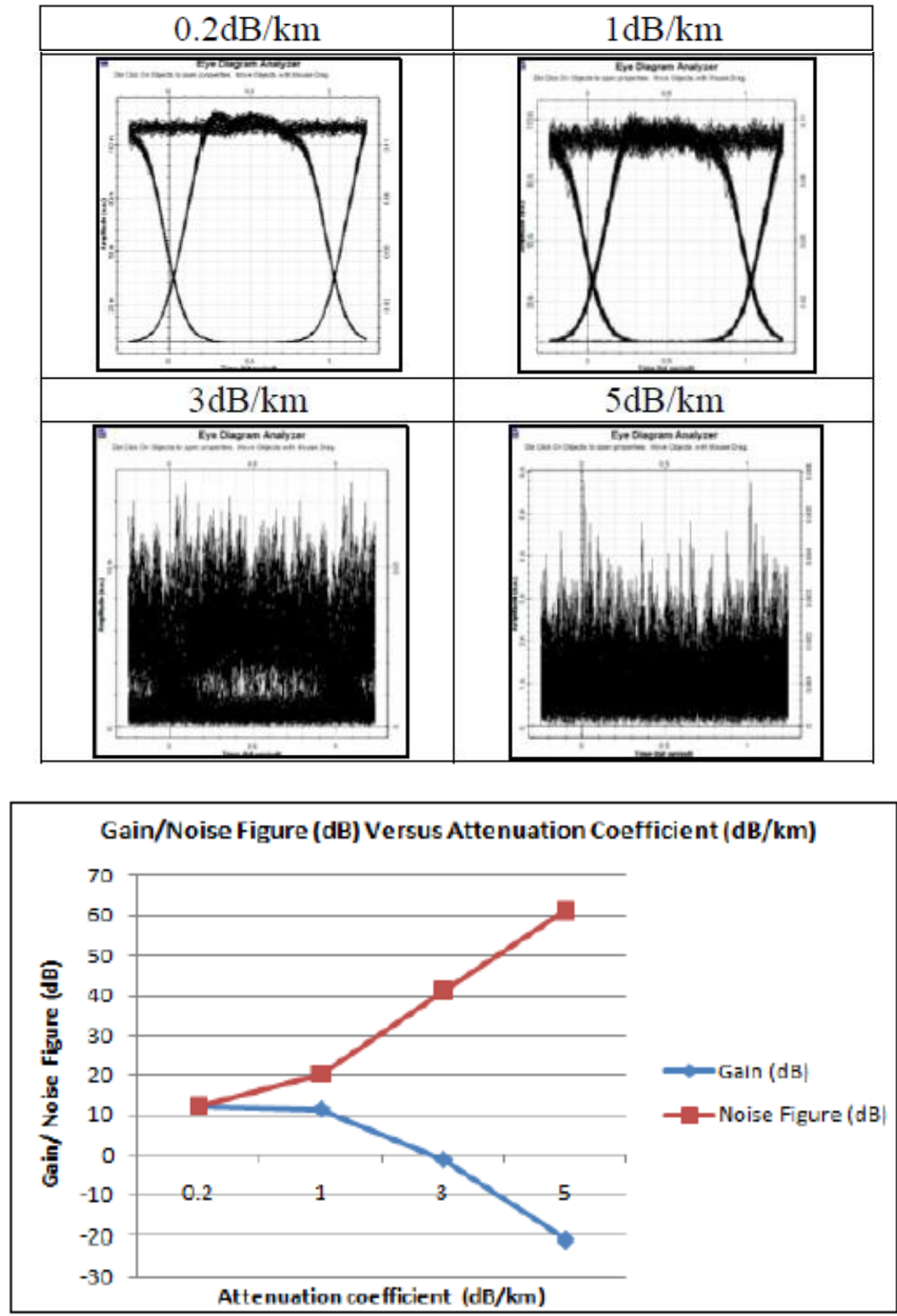

Figure 7: Gain/noise figure versus attenuation coefficient.

In this project, the transmission system with the good performance and characteristics is designed, such as the low transmission loss so that the transmission will be more effectively. The optical fiber is used for transmitting the signal as shown in the block diagram and modelling. From the design, the optical fiber 
transmission system can be combined with the modulator which can modulate the output signals. Moreover, the transmission system consists of optical amplifier which can be used to reduce the fiber loss and amplify the signal before being received by photo detector PIN at the receiver part [7]. There are different parameters which include output power $(\mathrm{dBm})$, attenuation coefficient $(\mathrm{dB} / \mathrm{km})$ at cable section and gain $(\mathrm{dB})$ at receiver will be investigated in order to determine the most suitable setting for a high performance optical transmitter. By analyzing data on Table 2, it shows that the length of fiber is directly proportional to the value of noise figure. From Figure 5, it is shown that with increasing fiber length, the gain decreases with further increasing length while the noise figure increase linearly as increasing length.

Table 4 shows the output readings which are tabulated by varying the input power while the data of gain/noise figure versus input power is plotted in Figure 6. From Figure 6, it is observed that with increasing input power, the gain decreases with increasing input power while the noise figure is increase gradually as the input power increase. Meanwhile, the output power is decreasing when the input power is increased. Since EDFA is used as the optical amplifier, output power will indicate that the optical amplifier will saturate or the gain has been compressed. The reason is that the power source of the amplifier, the number of excited erbium atoms or the number of available electron-hole pairs, is depleted.

Table 6 shows the output readings are obtained by varying the attenuation coefficient at cable section. From the table, it is obvious that when the attenuation coefficient is increased, the noise figure will increase as well while the gain is decreasing when the attenuation coefficient is increased. The gain is the ratio of the amplifier output signal to the input power signal. Noise figure is a measure of how much noise the amplifier adds to the signal.

\section{ConClusion}

From the design and simulation of optical transmission system, the journals related about optical transmission system have been discovered and studied in order to propose the design idea for a simulation of optical transmission system. The optical transmission system has common components like other communication system which consists of information source (input), transmitter, transmission channel (fiber optic), receiver and the destination (output). The system will transmit information using optical carrier wave from transmitter to receiver via optical fiber. Based on the research, the transmission system block diagram (Figure 3) has been designed which consists of laser light as the source, modulator, single mode optical fiber as the channel, fiber Bragg grating (FBG) as the dispersion compensator, optical amplifier and the photo detector as the light detector. Then, the optical transmission system has been modeled by using OptiSystem simulator as shown in Figure 4 in order to investigate different parameters of the system.From the simulation result, it can conclude that the optical fiber length and the attenuation coefficient are directly proportional to the noise figure. The noise figure is a measure of how much noise the amplifier adds to the signal. While the gain is getting lower with the increasing length. On the other hand, the output power is decreased although the input power is increased due to the usage of EDFA and the gain has been compressed. It is because the power source of the amplifier, the number of excited erbium atoms or the number of available electron-hole pairs, are depleted..

\section{Acknowledgements}

First of all, the special appreciation and thanks go to UniversitiTeknikal Malaysia Melaka for providing the invaluable fiber optic knowledge and the necessary guidance as well as encouragement in completing this paper. The supervision and support are truly help the progression and smoothness of this project. Moreover, the great deals appreciated go to the contribution from every team members for the valuable shares, opinions and resources provided in completing the report. The co-operation is much indeed appreciated.

\section{REFERENCES}

[1] S. O. Mohammadi, SaeedMozzaffari and M. Mahdi Shahidi, "Simulation of a transmission system to compensate dispersion in an optical fiber by chirp gratings.” International Journal of the Physical Sciences, Vol. 6(32), pp. 7354 - 7360,2 December, 2011.

[2] M. Litchinitser, J. Eggleton, and B. Patterson, "Fiber Bragg Gratings for Dispersion Compensation in Transmission: Theoretical Model and Design Criteria for Nearly Ideal Pulse Recompression”, Journal OfLightwave Technology, Vol. 15, No. 8, August 1997

[3] Jim Jachetta, "Fiber-Optic Transmission Systems". New York 2001.

[4] Toru Mizunami, Member; OSA, Tzvetanka V. Djambova, Tsutomu Niiho, and Sanjay Gupta."Bragg Gratings in Multimode and FewMode Optical Fibers".Journal of Lightwave Technology, Vol. 18, No. 2, February 2000.

[5] MohamadHasrulAriffin Bin MohdBadri, "A Cost Effective Broadband ASE Light Source Based FTTH", thesis, page 20-26.

[6] Chong Wing Keong, K R Subramanian, V K Dubey, “Optical Fiber System for Video and Telemetry Signal.” Singapore Polytechnic, Electronics and Comm Engineering, School of Electrical and Electronic Engineering, Nanyang Technology University, Singapore.

[7] Nabil AbdRabou, Hiroaki Ikda, Hirofumi Yoshida, Shigenobu Shinohara, “ Optical Fiber Wideband RF Signal Transmission System for Remote Data Sensing”. Shizuoka University, 3-5-1, Joboku, Hamamatsu 432, Japan.2009 